\title{
UPAYA PENINGKATAN HASIL BELAJAR SISWA KELAS X MIPA-1 PADA MATERI GERAK MELINGKAR BERATURAN MELALUI METODE LEARNING START WITH A QUESTION (LSWQ) DI SMA NEGERI 1 GLUMPANG TIGA TAHUN PELAJARAN 2020-2021
}

\author{
Cut Nurmala \\ SMAN 1 Glumpang Tiga \\ Email: cutnurmala.ta@gmail.com
}

\begin{abstract}
The purpose of this study was to find out that the Learning Start With A Question learning method could increase students' interest and cognitive learning outcomes in class X MIPA-1 students of SMA Negeri 1 Glumpang Tiga in the 2020/2021 academic year. This research is classified as an experimental research with one group pretest posttest design. The population in this study were all students of class X MIPA-1 SMA Negeri 1 Glumpang Tiga for the 2020/2021 academic year. Sampling was carried out using a simple randoms sampling technique, which then obtained class $X$ MIPA-1 as a sample. The increase in cognitive learning outcomes is known from the average pretest and posttest scores of students, while the increase in interest is known from the average score of the questionnaires given before and after learning. The test used to determine the increase in student interest and learning outcomes is showing an increase in student cognitive learning outcomes by Padas Cycle I, the results of the pree test show that there are 13 students who completed or $43.33 \%$ with an average score of 67.5 and post test results. There were 21 students who completed or $70 \%$ with an average score of 72.5. in Cycle II for the pree test of students who completed there were 15 people or $50 \%$ with an average score of 70.83 and in the post-test students who completed there were 28 people or $93.33 \%$ with an average score of 81.5 . Based on the results of the analysis, it can be concluded that the Learning Start With A Question learning method can be used to increase the interest and learning outcomes of physics students in class $X$ MIPA-1 SMA Negeri 1 Glumpang Tiga for the 2020/2021 academic year.
\end{abstract}

Keywords: Interest, Learning Outcomes, Learning Start With A Question

\begin{abstract}
ABSTRAK
Tujuan penelitian ini untuk mengetahui bahwa metode pembelajaran Learning Start With A Question dapat meningkatkan hasil belajar kognitif siswa pada siswa kelas X MIPA-1 SMA Negeri 1 Glumpang Tiga tahun pelajaran 2020/2021. Penelitian yang dilakukan tergolong sebagai penelitian eksperimental dengan one group pretest posttest design. Populasi dalam penelitian ini adalah semua siswa kelas X MIPA-1 SMA Negeri 1 Glumpang Tiga Tahun Pelajaran 2020/2021. Pengambilan sampel dilakukan dengan teknik simple randoms ampling, yang kemudian diperoleh kelas X MIPA-1 sebagai sampel. Peningkatan hasil belajar kognitif diketahui dari nilai rata-rata pretest dan posttes siswa, sedangkan peningkatan minat diketahui dari skor rata-rata angket yang diberikan sebelum dan setelah pembelajaran. Uji yang digunakan untuk mengetahui peningkatan minat dan hasil belajar siswa adalah menunjukkan adanya peningkatan hasil belajar kognitif siswa sebesar Padas Siklus I hasil pree test menunjukkan siswa yang tuntas ada 13 orang atau 43,33\% dengan nilai rata-rata 67,5 dan hasil post test siswa yang tuntas ada 21 orang atau $70 \%$ dengan nilai rata-rata 72,5 . pada Siklus II untuk pree tes siswa yang tuntas ada 15 orang atau $50 \%$ dengan
\end{abstract}


Jurnal Sains Riset (JSR)

p-ISSN 2088-0952, e-ISSN 2714-531X

http://journal.unigha.ac.id/index.php/JSR

DOI. $10.47647 /$ jsr.v10i12

nilai rata-rata 70,83 dan pada post test siswa yang tuntas ada 28 orang atau 93,33\% dengan nilai rata-rata 81,5. Berdasarkan hasil analisis dapat disimpulkan bahwa metode pembelajaran Learning Start With A Question dapat digunakan untuk meningkatkan minat dan hasil belajar fisika siswa lkelas X MIPA-1 SMA Negeri 1 Glumpang Tiga Tahun Pelajaran 2020/2021.

Kata Kunci: Minat, Hasil Belajar, Learning Start With A Question

\section{PENDAHULUAN}

Pendidikan merupakan proses yang sangat menentukan untuk perkembangan individu dan perkembangan masyarakat. Kemajuan suatu masyarakat dapat dilihat dari perkembangan pendidikanya. Menurut Ihsan (2008:1), "pendidikan adalah usaha manusia untuk menumbuhkan dan mengembangkan potensi-potensi pembawaan baik jasmani maupun rohani sesuai dengan nilai-nilai yang ada di dalam masyarakat dan kebudayaan". Tujuan pendidikan tersebut dapat tercapai secara optimal apabila guru sebagai pendidik selalu mengembangkan proses pembelajaran yang sesuai dengan kondisi terkini. Salah satu masalah yang dihadapi untuk meningkatkan mutu pendidikan adalah proses pembelajaran yang masih lemah.Trianto (2007:2) menyatakan hasil belajar yang masih rendah disebabkan oleh proses pembelajaran yang didominasi oleh pembelajaran tradisional. Pembelajaran tradisional menggunakan metode ceramah dengan suasana kelas cenderun gteachercentered sehingga membuat siswa pasif.

Mata pelajaran fisika merupakan salah satu mata pelajaran sains yang diharapkan sebagai sarana mengembangkan kemampuan berpikir analitis deduktif dengan menggunakan konsep dan prinsip fisika untuk menjelaskan berbagai peristiwa alam.Tujuan pembelajaran mata pelajaran fisika SMA yang dicanangkan Depdiknas (2006:443) adalah: (i) sebagai sarana meningkatkan keyakinan terhadap tuhan YME, (ii) memupuk sikap ilmiah dan dapat bekerjasama dengan orang lain,(iii) memberi pengalaman untuk dapat merumuskan masalah dan mengajukan hipotesis, (iv) mengembangkan kemampuan berpikir analisis induktif dan deduktif,dan (v) menguasai pengetahuan,konsep,dan prinsip fisika, serta memiliki pengetahuan, keterampilan, dan sikap ilmiah.

Hasil belajar mata pelajaran fisika yang terukur pada nilai rata-rata ulangan umum masih kurang memuaskan dan membawa keprihatinan para pendidik khususnya guruguru fisika. Minat untuk mempelajari konsep-konsep fisika juga masih rendah. Hasil penelitian Hari (2008) sebagaimana dikutip oleh Samudra et al. (2014:1) menyatakan bahwa fisika adalah mata pelajaran yang sulit untuk dipelajari dan tidak disukai oleh siswa khususnya siswa SMA. Kondisi pembelajaran fisika yang seperti itu dan kurangnya minat belajar siswa, menyebabkan ketuntasan pembelajaran fisika relatif rendah.

SMA Negeri 1 Glumpang Tiga merupakan sekolah unggulan di Kabupaten Pidie. Nilai rata-rata siswa yang terukur pada raport tinggi, termasuk mata pelajaran fisika.Kegiatan belajar mengajar dikelas menggunakan kurikulum 2013, akan tetapi metode pembelajaran yang sering digunakan oleh guru adalah metode ceramahyang berpusat pada guru (teacher-centered). Metode ceramah menyebabkan siswa menjadi cepat bosan dan kurang aktif dalam belajar. Oleh karena itu perlu ada inovasi baru yang bisa merubah pendekatan pembelajaran dari teacher-centered menjadi student-centered,agar siswa menjadi lebih aktif dan kondisi kelas menjadi lebih menyenangkan.

Dari penjelasan diatas, dapat diketahui bahwa pembelajaran fisika di SMA Negeri 1 Glumpang Tiga masih belum maksimal. Perlu ada metode pembelajaran yang lebih baik dari pada metode ceramah. Metode pembelajaran yang digunakan harus mampu memunculkan keterlibatan siswa secara aktif dalam pembelajaran, yang meliputi 
kemampuan untuk bertanya, menjawab pertanyaan, dan mengungkapkan gagasan dalam diskusi kelompok sehingga aktivitas siswa dalam pembelajaran dan hasil belajar siswa akan meningkat.

Salah satu metode pembelajaran yang dapat digunakan untuk meningkatkan aktivitas siswa dikelas adalah metode Learning Starts with AQuestion. Zaini et al. (2008:44) menyatakan "Learning Starts with A Question adalah suatu strategi pembelajaran aktif dalam bertanya". Metode ini mengharuskan siswa untuk membaca materi terlebih dahulu dengan tuuan agar siswa aktif dalam bertanya Dengan membaca, maka siswa memiliki gambaran tentang materi yang akan dipelajari sehingga apabila dalam pembelajaran terjadi kesalahan konsep, dapat dibahas serta dibenarkan secara bersama-sama. Pembelajaran dengan metode Learning Starts With Aquestion dimulai dari pertanyaan siswa yang bekerja dalam kelompok kecil yang berjumlah 4-6 orang.Metode ini dapat merangsang keaktifan belajar siswa karena siswa akan saling berkelompok dalam membuat pertanyaan dan berbagi pengetahuan ketika menyelesaikan tugas. Dari keterangan di atas, penulis mencoba melakukan penelitian dengan metode pembelajaran Learning Start with A Question untuk diterapkan dalam pembelajaran fisika di SMA Negeri 1 Glumpang Tiga.

\section{METODE PENELITIAN}

Kegiatan penelitian ini dilaksanakan di SMA Negeri 1 Glumpang Tiga khususnya pada siswa kelas X MIPA-1 SMA Negeri 1 Glumpang Tiga Tahun Pelajaran 2020/2021 pada bulan September sampai November 2020. Pada penelitian ini, yang menjadi sampel adalah siswa kelas X MIPA-1 SMA Negeri 1 Glumpang Tiga. Penulis mengambil sampel dengan teknik random sampling,yaitu teknik pengambilan sampel yang mencampur subjek-subjek di dalam populasi sehingga semua subjek dianggap sama. Dalam penelitian ini pengumpulan data menggunakan metode observasi, dokumentasi, angket dan tes. tes tertulis yang telah dirancang oleh peneliti sesuai dengan tujuan yang telah tertuang di dalam kisi-kisi soal. Tes tertulis dilaksanakan pada setiap akhir siklus. Analisis data yang digunakan dalam penelitian ini adalah teknik analisis deskriptif, yaitu: Analisis deskriptif komparatif hasil belajar dengan cara membandingkan hasil belajar pada siklus I dengan siklus II dan membandingkan hasil belajar dengan indikator pada siklus I dan siklus II.

\section{HASIL PENELITIAN DAN PEMBAHASAN \\ A. Deskripsi Siklus I}

Tabel 1. Persentase nilai pre test dan post test peserta didik pada Siklus I

\begin{tabular}{lcccc} 
& \multicolumn{2}{c}{ Pre test } & \multicolumn{1}{c}{$\begin{array}{c}\text { Post } \\
\text { Test }\end{array}$} \\
\cline { 3 - 5 } & & & & \\
\cline { 1 - 4 } Kategori & & & & \\
\cline { 1 - 5 } Nilai & Frekuensi & $\%$ & $\begin{array}{c}\text { Frekuen } \\
\text { si }\end{array}$ & \% \\
\hline Nilai $<70$ & 17 & 56,66 & 9 & 30 \\
\hline Nilai $\geq 70$ & 13 & 43,33 & 21 & 70 \\
\hline Jumlah & $\mathbf{3 0}$ & $\mathbf{1 0 0}$ & $\mathbf{3 0}$ & $\mathbf{1 0 0}$ \\
\hline
\end{tabular}

Terdapat peningkatan frekuensi/ jumlah peserta didik yang nilainya $\geq 70$ pada pre test dan post test. Pada saat pretest, peserta didik yang nilainya $\geq 70$ sebanyak 13 anak atau 43,33\%, sedangkan pada post test peserta didik yang nilainya $\geq 70$ sebanyak 21 anak atau $70 \%$. Sehingga peningkatannya sebesar 26,67\%. Sehingga dapat dilihat bahwa adanya pembelajaran kooperatif dengan teknik $L S W Q$ dapat meningkatkan prestasi belajar peserta didik kelas X MIPA1. Namun belum dapat dikatakan berhasil karena persentase belum mencapai kriteria ketuntasan yaitu sebesar $75 \%$ atau sebanyak 
21 peserta didik mendapat nilai $\geq 70$.

\section{B Deskripsi Siklus II}

Tabel 2. Persentase nilai pre test dan post test peserta didik pada Siklus II

\begin{tabular}{ccccc}
\hline $\begin{array}{c}\text { Kategori } \\
\text { Nilai }\end{array}$ & \multicolumn{2}{c}{ Pre test } & \multicolumn{2}{c}{ Post test } \\
\hline & $\begin{array}{c}\text { Frekuen } \\
\text { si }\end{array}$ & $\%$ & Frekuen & $\%$ \\
& 15 & 50 & si & \\
\hline Nilai $<70$ & 15 & 50 & 28 & 93,33 \\
\hline Nilai $\geq 70$ & & & & \\
\hline Jumlah & $\mathbf{3 0}$ & $\mathbf{1 0 0}$ & $\mathbf{3 0}$ & $\mathbf{1 0 0}$ \\
\hline
\end{tabular}

Tabel diatas menunjukan ada peningkatan antara pre test dan post test. Pada pre test persentase peserta didik yang memperoleh nilai $\geq 70$ hanya sejumlah $50 \%$ atau 15 anak, sedangkan pada post test meningkat menjadi 93,33\% atau sebanyak 28 anak. Hal ini menunjukan bahwa penerapan pembelajaran Learning Start With a Question dapat meningkatkan prestasi belajar dan termasuk dalam kategori tinggi. Sehingga dapat dikatakan berhasil.

\section{Deskripsi Antar Siklus}

Tabel 3. Perbandingan Nilai Pre Test dan Post test Siklus I dan Siklus II.

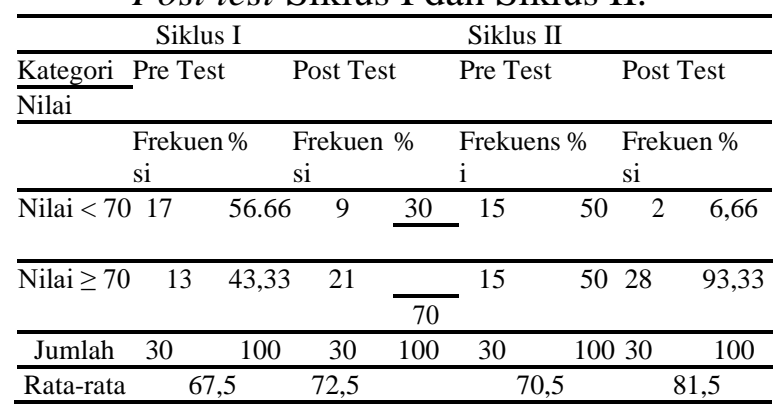

Tabel di atas menujukan ada peningkatan nilai rata-rata pre test dan post test baik pada siklus I maupun siklus II. Pada siklus I, rata-rata nilai pre test sebesar 67,5 dengan jumlah peserta didik yang tuntas atau memiliki nilai $\geq 70$ sebanyak 13 atau 43,3\% peserta didik. Namun terjadi peningkatan setelah dilaksanakan pembelajaran dengan teknik $L S W Q$ yaitu nilai rata-rata post test menjadi 72,5 dan yang meraih nilai $\geq 70$ sebanyak 21 atau $70 \%$ peserta di dik. Hal tersebut menunjukan terjadi peningkatan meski belum mencapai kriteria ketuntasan yang diharapkan. Begitu pula pada siklus II, nilai rata-rata siswa mengalami peningkatan dari 70 dengan jumlah peserta didik yang tuntas atau memiliki nilai $\geq 70$ sebanyak 15 atau $50 \%$ peserta didik, rata-rata nilai menjadi 70,83 dengan jumlah peserta didik yang tuntas atau memiliki nilai $\geq 70$ sebanyak 28 peserta didik atau $93,33 \%$.

Pada siklus ke II ini, rata-rata nilai dan jumlah peserta didik yang tuntas KKM sudah memenuhi target yang diharapkan yakni ratarata nilai mencapai 78,88 dan jumlah peserta didik yang tuntas KKM mencapi 93,33\%\% dari jumlah peserta didik kelas X MIPA-1. Sehingga dapat dikatan bahwa pembelajaran teknik $L S W Q$ dapat meningkatkan prestasi belajar fisika peserta didik kelas X MIPA-1.

\section{SIMPULAN DAN SARAN}

Berdasarkan hasil penelitian yang dilakukan dapat disimpulkan bahwa metode pembelajaran Learning Start With a Question dapat meningkatkan hasil belajar kognitif dan afektif berupa minat pada siswa kelas $\mathrm{X}$ MIPA-1 SMA Negeri 1 Glumpang Tiga Tahun Pelajaran 2020/2021. Dengan demikian disarankan kepada guru-guru di SMAN 1 Glumpang Tiga dapat menerapkan metode pembelajaran matematika pada materi lainnya guna meningkatkan hasil belajar siswa dan sebagai alternatif dalam memperbaiki kualitas pendidikan di SMAN 1 Glumpang tiga.

\section{DAFTAR PUSTAKA}

Arikunto,S. 2006. Dasar-Dasar Evaluasi Pendidikan. Jakarta: Bumi Aksara.

2009. Prosedur Penelitian: Suatu Pendekatan Praktik .Jakarta: Rineka Cipta. 
Departemen Pendidikan Nasional, 2006. Permendiknas Nomor 22 Tahun 2006 tentang Standar Isi. Jakarta: BSNP.

. 2008. Kamus Bahasa Indonesia. Jakarta: Pusat Bahasa.

Hamalik,O. 2009. Proses Belajar Mengajar. Jakarta: Bumi Aksara.

Ibrahim, R. \& N. Syaodih S. 2003. Perencanaan Pengajaran. Jakarta: Rineka Cipta.

Ihsan,F. 2008. Dasar-dasar Kependidikan. Jakarta: Rineka Cipta Karya.

Kusuma,D.L.\&I.N. Parta. 2013. Peningkatan Keaktifan Siswa Melalui Pembelajaran dengan Strategi Learning Start With A Question pada Materi Segitiga dan Segiempat untuk Siswa kelasVII-H SMPN 1 Blitar. FMIPA Universitas Negeri Malang: 7.Tersedia http://jurnalonline. um.ac.id/ data/ artikel/ artikel BF44977EFB0B3B000F 565225136BCA31. Pdf [diakses1811-2014].

Margono,S.2003. Metodologi Penelitian Pendidikan. Jakarta: RinekaCipta.

Marno \& M Idris. 2009. Strategi \& Metode Pembelajaran. Yogyakarta: Ar-ruzz Media Group.

Pemerintah Republik Indonesia. 2003.Undang-Undang Republik Indonesia No.20Tahun 2003 tentang Sistem Pendidikan Nasional. Jakarta.

Phopam, W.J. \& E.L. Baker. 2005. Teknik Mengajar Secara Sistematis. Jakarta: Rineka Cipta.
Riswani,E.F.\&A.Widayati. 2012. Model Active Learning dengan Teknik Learning Start With A Question dalam Peningkatan Keaktifan Peserta Didik pada Pembelajaran Akuntansi Kelas XI Ilmu Sosial 1SMA Negeri 7 Yogyakarta Tahun Ajaran 2011/2012. Jurnal Pendidikan Akuntasi Indonesia, 10(2): 18-19. Tersedia di http://journal.uny.ac.id/index.php/jp akun/article/view/910 [diakses1811-2020].

Samudra,G. B.etal.2 014. Permasalahanpermasalahan yang Dihadapi Siswa SMA di Kota Singaraja dalam Mempelajari Fisika. $E$ journal Program Pascasarjana Universitas Pendidikan Ganesha, 4(1): 1-2. Tersedian di http://pasca.undiksha.ac.id/ejournal/index.php/jurnal_ipa/article /view/1093 [diakses10-12-2020].

Sanjaya,W. 2005. Pembelajaran dalam Implementasi Kurikulum Berbasis Kompetensi. Jakarta: Kencana Prenada Media Group.

Saputri,G.E.2011. Meningkatkan Minat dan Hasil Belajar Siswa Melalui Metode Learning Starts With A Question pada Siswa Kelas VII SMPN 2 Tegowanu Tahun Ajaran 2010/2011. Skripsi. Semarang: FMIPA Universitas Negeri Semarang.

Silberman, M.L. 2009. Active Learning:101 Strategi Pembelajaran Aktif. Yogyakarta: Pustaka Insan Madani.

Sudijono, A.2006 .Pengantar Evaluasi Pendidikan. Jakarta: Raja Grafindo Persada.

Sudjana. 2002. Metode Statistika. Bandung: 
Tarsito.

Sugiyono. 2009. Metode Penelitian Pendidikan: Pendekatan Kuantitafif, Kualitatif dan $R \& D$. Bandung: Alfabeta.

Supriyadi. 2010. Teknologi Pendidikan Fisika. Yogyakarta: FMIPA UNY.Surya,Y.2003. Fisikaitu Mudah. Jakarta: Bina Sumber Daya Mipa.

Susatyo, E.B. et al. 2009. Penggunaan Model Learning Start With A Question danSelf Regulated Learning pada Pembelajaran Kimia. Jurnal Inovasi
Pendidikan Kimia 3 (1):411-412. Tersedia di http://journal. unnes.ac.id/nju/index.php/JIPK/arti cle/view/1273/1324[diakses18-112020].

Syah, M. 2010. Psikologi Pendidikan dengan Pendekatan Baru. Bandung: Remaja Rosda karya.

Syah,M.2003. Psikologi Belajar. Jakarta: Raja Grafindo Persada

Tipler,P.A.1998. Fisika Untuk Sains dan Teknik: Edisi Ketiga. Jakarta: Erlangga 